\section{Pediatria \\ Crianças COM hÉRnIA IngUINAL PODEM SER OPERADAS POR CIRURGIÃO GERAL?}

A herniorrafia inguinal constitui uma das cirurgias mais freqüentes realizadas na criança. Tendo por base o argumento de que muitos hospitais ou cidades isoladas não dispõem de cirurgião-pediatra, é prática comum nestes locais que crianças com hérnia inguinal sejam operadas por cirurgião geral. Em trabalho realizado no Canadá, em que se coletaram dados de diferentes hospitais, públicos e privados, da província de Ontário, os autores estudaram 20.545 crianças submetidas à cirurgia de correção de hérnia inguinal: um grupo (50,3\% dos casos) foi operado por cirurgião pediatra, e outro $(49,7 \%)$ por cirurgião geral. Foram excluídos recém-nascidos e prematuros, bem como crianças com outras afecções clínicas ou cirúrgicas. O tempo de duração da cirurgia, período de internação hospitalar e complicações do período pós-operatório imediato foram semelhantes nos dois grupos. A verificação mais importante foi que ocorreu maior índice de recidivas tardias no grupo de crianças operadas por cirurgião geral.

A correção da hérnia inguinal na criança é procedimento delicado e requer cuidados de ordem técnica, pelo perigo de lesão do ducto deferente e dos vasos responsáveis pela irrigação do testículo. Recém-nascidos e prematuros são mais sujeitos a tais complicações, motivo pelo qual foram excluídos do estudo. Apesar de serem incluídas no estudo apenas as crianças maiores, concluiu-se ainda que a criança com hérnia inguinal deve ser operada por cirurgião-pediatra

Uenis Tannuri

Referência

Borenstein SH, To T, Wajja A, Langer JC. Effect of subspecialty training and volume on outcome after pediatric inguinal hernia repair . J Pediatr Surg 2005; $40: 75-80$

\section{Climica Médica \\ É CLARO 0 PAPEL DA ANTICOAGULAÇÃO EM HIPERTENSÄO PULMONAR?}

Nos últimos anos, várias alternativas terapêuticas vêm sendo desenvolvidas para o tratamento da hipertensão pulmonar, com particular atenção na hipertensão arterial pulmonar idiopática. Entre as opções mais recentes, temos os prostanóides (seja sob a forma endovenosa, inalatória ou subcutânea), inibidores de fosfodiesterase e os antagonistas dos receptores de endotelina. Outras classes de medicamentos são utilizadas para o manejo de pacientes com hipertensão pulmonar, constituindo o que era chamado de tratamento convencional ou não específico da hipertensão pulmonar; destacamos aí o uso de anticoagulantes orais.
O uso de anticoagulação oral em pacientes com hipertensão arterial pulmonar idiopática é fundamentado pelo resultado de três estudos retrospectivos que evidenciaram melhora na sobrevida dos pacientes em uso efetivo de anticoagulação. $O$ racional para o uso de anticoagulantes orais é atribuído à disfunção endotelial presente como fenômeno fisiopatológico, cada vez mais reconhecido em pacientes com hipertensão pulmonar, que por sua vez levaria a um ambiente propício à trombose in situ'.

Mais recentemente, porém, vem crescendo o número de evidências que indicam a presença de um processo inflamatório marcante na fisiopatologia da hipertensão pulmonar, como por exemplo o aumento dos níveis de citocinas, quimiocinas e mesmo o reconhecimento da alteração determinada por genes da família do TGF- $\beta^{2}$. O que torna mais interessante essa observação é o fato de que os anticoagulantes sabidamente interferem no processo inflamatório, uma vez que a ativação plaquetária tem relação estreita com a modulação/ativação da resposta leucocitária ${ }^{3}$.

Recentemente, em um estudo avaliando possíveis vias fisiopatológicas de ativação plaquetária/ inflamação em hipertensão pulmonar, mais especificamente o papel da proteína ligadora do CD40, evidenciou que os níveis da mesma em pacientes em uso de dicumarínicos era bastante diminuído em relação a pacientes sem anticoagulação, sugerind o que o papel antitrombótico atribuído aos dicumarínicos talvez não seja sua única via de ação, podendo existir um potencial efeito anti-inflamatório ${ }^{4}$.

Esse tipo de observação abre novas perspectivas de estudo também para as demais formas de hipertensão pulmonar, em que notadamente o processo inflamatório é mais intenso, como na hipertensão pulmonar associada às doenças do tecido conectivo, à doença pulmonar obstrutiva crônica, às doenças intersticiais pulmonares ou ainda ao vírus da imunodeficiência humana.

Até o momento, as evidências para o uso de anticoagulantes em hipertensão pulmonar se restringem à hipertensão pulmonar associada à embolia crônica e à hipertensão arterial pulmonar. Ainda assim, nesse último caso, fundamentadas em estudos retrospectivos. Passa a existir, porém, um novo caminho de estudos a ser explorado para tão conhecida classe de drogas.

Rogério Souza

Carlos Jardim

MÔNICA LAPA

Referências

I. Humbert M, Sitbon O, Simonneau G. Treatment of pulmonary arterial hypertension. N Engl] Med 2004;35 I ( I 4): | 425-36.

2. Dorfmuller P, Perros F, Balabanian K, Humbert M. Inflammation in pulmonary arterial hypertension. Eur Respir J 2003;22(2):358-63.

3. Esmon CT. Role of coagulation inhibitors in inflammation. Thromb Haemost 200I;86(I):5I-6.

4. Damas JK, Otterdal K, Yndestad A., Aass H, solum NO, Froland SS, et al. Soluble CD40 ligand in pulmonary arterial hypertension: possible pathogenic role of the interaction between platelets and endothelial cells. Circulation 2004; I 10(8):999-1005. 